\title{
POLÍTICAS Y PROBLEMÁTICA DE LA FORMACIÓN DEL PROFESORADO EN ESPAÑA (1969-2004): la Revista de Educación en el contexto de la agenda educativa internacional
}

\begin{abstract}
Policy and the problem of teacher training in Spain (1969-2004): the Magazine of Education in the context of the international education agenda
\end{abstract}

\section{Antón Costa Rico}

Professor Doutor da Universidade de Santiago de Compostela, Galicia - España, email: anton.costa@usc.es

\section{Resumen}

O presente contributo, de natureza socio-histórica, tenta presentar e explicar como aconteceu o cruzamento de liñas que se rexistrou en España, nos últimos trinta anos do século XX, os da transición e asentamento da democracia política, en relación coa práctica empírica, a política educativa e os discursos académicos, de alcance internacional neste caso, en canto á formación do profesorado de niveis non universitarios. Sostense que a práctica empírica foi, sobre 
todo, disonante con respecto ás liñas que se ían trazando nas outras esferas, por manterse nun plano máis artesanal e conservador, o que non impediu, sen embargo, a existencia de manifestacións desta práctica empírica, a cargo de distintos sectores do profesorado con conviccións, nuns casos, liberais-pragmáticas, e noutros sociocríticas, que tiveron unhas como as outras un apreciable grao de confluencia coa esfera dos discursos, sobre todo no caso sociocrítico e referidos ao modelo do "profesor reflexivo", entre os pasados anos oitenta e os noventa. Saliéntanse, a este respecto, o papel desempeñado pola Revista de Educación, institucional e académica, e os significados dos Institutos rexionais de Ciencias da Educación e dos Centros de profesores, como estruturas administrativas para a formación do profesorado, e imaxes representativas de dous entendementos políticos da formación do profesorado.

Palabras-clave: Formación do profesorado. Profesor eficaz. Profesor reflexivo. Competencias. Política educativa.

\section{Abstract}

The present contribution is of a socio-historical nature and aims to present and explain how there was an amalgamation of policies during the last thirty years of the $20^{\text {th }}$ century - those of the transition to and consolidation of political democracy-insofar as empirical practices, educational policy and academic reasoning, of an international scope in this case, with regard to non-university teaching staff. It is maintained that empirical practices were, above all, out of tune with respect to those policies that had been drawn up in other fields, due to the fact that they were kept on a more artisan and conservative plane; nevertheless, this did not stop the appearance of demonstrations of this empirical practice at the hands of different sectors of the teaching staff, who had liberalpragmatic convictions in some cases and socio-critical in others. During the nineteen eighties and nineties, all these manifestations had a clear-cut degree of common ground with the field of reasoning, above all in the socio-critical context and with reference to the "reflexive teacher" model. To this respect, it is worth highlighting the role played by the institutional and academic journal Revista de Educación (Education Review), and the

Rev. Diálogo Educ., Curitiba, v. 9, n. 27, p. 215-248, maio/ago. 2009 
significance of the Institutos rexionais de Ciencias da Educacion (Regional Teacher Training Institutes) and of the Centros de profesores (Teacher Centres), as administrative structures for teacher training and as representative images of the two policy trends with respect to teacher training.

Keywords: Teacher training. Efficient teacher. Reflexive teacher. Fields. Educational policy.

\section{Modernización estructural y reformas educativas en España}

Hacia el final de la década de los pasados años sesenta, en España, que se hallaba instalada aún en un régimen político autoritario (el franquismo), comenzaron a ser visibles las consecuencias modernizadoras de una política económica en la que se entremezclaban medidas económicas desarrollistas e industrialistas, con otras pertenecientes al acervo de recetas del liberalismo económico internacional. Aparecían nuevos desequilibrios económicos territoriales; una numerosa población laboral era emigrante en otros países europeos, desde donde sus recursos contribuían al fortalecimiento de la economía financiera española; se producía una intensa y desordenada urbanización de la sociedad española, mientras la economía agraria reducía su participación en el producto interior bruto; y aumentaban también las demandas escolarizadoras, que no encontraban respuesta social y política adecuada en un sistema y en unos marcos pensados para una educación de orientación elitista.

En este contexto se fue abriendo paso una significativa insatisfacción social, que en los medios universitarios y aún incluso en el sector de los centros públicos de educación secundaria conduciría a una situación de conflictividad explícita manifestada en reivindicaciones, huelgas y manifestaciones, de ordinario reprimidas policialmente.

Será en estas circunstancias como comenzará a construirse un movimiento de opinión social y algunas experiencias escolares y pedagógicas que apuntaban hacia la crítica del modelo educativo dominante y hacia la formulación de perspectivas de renovación y de reforma; un movimiento más perceptible en las grandes ciudades de Barcelona y de Madrid, y también en el País Vasco.

En respuesta, el nuevo ministro de educación Villar Palasí y su equipo técnico afrontaron la necesidad de una reforma general de la educación en España, a cuyos efectos en 1969 se daría luz pública al crítico informe oficial La educación en España. Bases para una política educativa, desde donde se fundamentaron las bases

Rev. Diálogo Educ., Curitiba, v. 9, n. 27, p. 215-248, maio/ago. 2009 
de la Ley General de Educación de 1970. Un informe que señalaba el tradicionalismo y falta de funcionalidad social del sistema educativo y sus graves carencias y limitaciones. Al contrario, el sistema educativo que habría que formular debería reconocer el derecho de todos a una educación general básica obligatoria y gratuita entre los 6 y los 14 años de edad.

La nueva Ley nacía inspirada por los criterios del reformismo tecnocrático, auspiciado en aquellos momentos por la OCDE y el Banco Mundial, teniendo como fundamental mentor al técnico de relieve internacional y miembro del Opus Dei Ricardo Díaz Hochleitner. En esta misma dirección, la oficial Revista de Educación iba a realizar una aportación continua, bajo la dirección de José Blat Jimeno y del propio Díez Hochleitner, en su calidad de Presidente del Consejo de Redacción. En los años 1969 a 1972 se habla de modo constante de la reforma educativa y del modelo español de desarrollo educativo, con el acompañamiento del Comité de Cooperación Internacional para la reforma de la educación española, sostenido por la UNESCO.

Las cuestiones que ocuparán mayor atención son aquellas más relacionadas con una perspectiva tecnocrática de la reforma: en 1970 se habla de programación y de la taxonomía de los objetivos de la educación, del rendimiento escolar y de la evaluación educativa, y de la enseñanza programada y automatizada. También se habla de políticas y de estrategias de innovación tecnológica educativa.

La Ley General de Educación nacía en un contexto institucional, político y social contradictorio; era presentada como una propuesta de espíritu tecnocrático diseñada por técnicos, con el visto bueno de organismos internacionales y por el impulso de los sectores "aperturistas" del capitalismo español y del equipo económico gubernamental en aquellos momentos dominante, como analizó Ignacio Fernández de Castro, ${ }^{1}$ respondiendo así más a una lógica capitalista que a la lógica política franquista, pero, por otra parte, nacía sujeta a la tradición cultural española dominante y a las presiones que diversos poderes fácticos imponían, entre ellos la propia Iglesia Católica.

Fundamentada en los principios meritocráticos de la teoría del capital humano se sitúa como final de un proceso de búsqueda de mayores niveles de eficacia educativa y de racionalidad científica, debiéndose señalar que en esta vía se incorporó el discurso de la pedagogía por objetivos, tyleriana y conductista, que con su lenguaje técnico, parecía ofrecer las garantías de planteamientos asépticos y no conflictivos, llegando a imponerse una concepción tecnológica al servicio del funcionamiento del sistema, al ofrecer la "seguridad" de la eficacia y de la eficiencia. Así, lo técnico, al menos formalmente, se imponía por vez primera a lo político, en cuanto al control curricular y al desarrollo de sus prácticas.

FERNÁNDEZ DE CASTRO, 1973. Vid. también LERENA ALESON, 1986.

Rev. Diálogo Educ., Curitiba, v. 9, n. 27, p. 215-248, maio/ago. 2009 
En este sentido, a su lado se desarrollaron: actividades y programas con algún contenido innovador, las agrupaciones flexibles del alumnado, la enseñanza individualizada, a menudo proclamada como enseñanza personalizada, la enseñanza en equipo, y una formación del profesorado centrada en la adquisición de destrezas técnicas, pero todo ello sin tener en cuenta los contextos reales de los procesos de enseñanza-aprendizaje, el contenido socializador de las estrategias de individualización didáctica, y otras consideraciones relacionadas con el contexto cultural, las nuevas demandas sociales, o la psicología del desarrollo y del aprendizaje.

Lo que se debería enseñar se indicaba a modo de objetivos operacionales de progresión creciente, lo que "facilitaba" instrumentalmente la evaluación, control y revisión de las distintas unidades, yéndose desde la globalización formativa hasta la capacitación instructiva a través de los diversos niveles y ciclos de enseñanza.

Se imponía, pues, una dimensión científico-técnica, que minusvaloraba cualquier otra consideración valorativa. $\mathrm{Al}$ respecto se extendió de modo omnímodo el poder de los textos (y de las fichas de individualización de la enseñanza y otros materiales concebidos para la autoinstrucción ${ }^{2}$ ) y de las editoriales, que condicionarán el modelo de cultura escolar, toda vez que los profesores, deslegitimados en cuanto a sus competencias y habilidades profesionales, o bien, se reafirmaron en su tradicional cultura docente, o bien, lo que fue más frecuente, se dejaron guiar por las pautas planificadas, programadas y organizadas desde los libros de texto y los materiales complementarios editados. Se seguía, en todo caso, el discurso científico avalado por las estructuras universitarias del conocimiento académico, lográndose una cierta conjunción entre el discurso científico-técnico, el administrativo-político y el de la práctica legitimada, ${ }^{3}$ de la que sólo se distanciaban crítica y creativamente aún muy pequeños y localizados núcleos de profesores.

Tras la salida ministerial del Equipo de Villar Palasí, en 1973, van a reaparecer los aspectos más conservadores y autoritarios, finalizando operativamente con un intento de renovación más formal que real. Aunque éste impulso político era sólo parte del panorama.

Frente a la tradicional cultura empírico-práctica, a los dominantes modelos cultural-educativos ligados al desarrollo del conocimiento experto, y frente también a la cultura expresada en el lenguaje normativo-administrativo, los rescoldos de la memoria de la renovación pedagógica republicana de

2 "Para adquirir determinados conocimientos y hábitos programados como objetivos", se decía en Vida Escolar en 1973.

3 Según la categorización construída por Escolano Benito en "Las culturas de la escuela en España. Tres cortes historiográficos", Pro-posiçoes, Universidade de Campinas, 2005.

Rev. Diálogo Educ., Curitiba, v. 9, n. 27, p. 215-248, maio/ago. 2009 
filiación laica, liberal y escolanovista, que permanecían agazapados en diversos rincones de la geografía social y escolar española, se pudieron avivar en Cataluña desde el comienzo de los años 50 , momento en que un grupo reducido de profesores comenzaron a considerar una perspectiva que hoy encajamos dentro del modelo crítico-reflexivo, que paulatinamente encontraría audiencia entre otros sectores del profesorado en España, aquellos que se situaban fuera de los entramados del franquismo.

Los ecos del Mayo parisino y estudiantil del 68, las aportaciones del psicoanálisis, de la pedagogía institucional, o de la sociología crítica marxista, la pedagogía liberadora de Freire, el discurso de la desescolarización, y, en particular, los textos producidos por Celestin y Élise Freinet, por sus compañeros franceses y por los italianos del "Movimento de Cooperazione Educativa", habían cambiado la forma de pensar la educación por parte de muchos profesores, jóvenes e inquietos, ya en los primeros años setenta, y en este sentido los textos que venimos de señalar componían las lecturas más preciadas, a pesar de no ser siempre bien digeridas, huérfanos de conceptos y de una básica formación pedagógica donde asentar las reflexiones procedentes de estas lecturas.

La muerte de Franco en 1975 marcaba el fin del régimen franquista y la propia monarquía comprendió la necesidad política de las libertades y de su institución a través de un proceso constitucional y democrático. En ello estaban comprometidos todos los variados sectores políticos de orientación democrática emergentes y sus varias plataformas de representatividad, de tal modo que durante varios años, y aún después de la aprobación de la Constitución democrática en 1978, que constitucionalizaba el derecho a la educación, se pueden observar dos escenarios en liza: el institucional, ligado a usos tradicionales ahora moderados, y el de los movimientos sociales organizados bajo el horizonte de un nuevo modelo de sociedad, que conllevaba, por igual, una alternativa democrática en el campo de la política educativa.

Y aquí la creatividad profesional y social fue extraordinaria entre los finales de los años setenta y los primeiros años ochenta, con múltiples manifestaciones e iniciativas, a menudo más voluntariosas que bien fundadas. Es el momento de las iniciativas editoriales con lecturas "de izquierda", de la aparición de nuevas revistas pedagógicas conectadas con esta nueva sensibilidad del profesorado, de los llamados y emergentes movimientos de renovación pedagógica, y de los congresos y encuentros organizados desde estos sectores, componiendo un escenario que desbordaba el plano oficial de la formación del profesorado; un escenario que se situaba igualmente más allá de la responsabilidad que oficialmente recaía en los Institutos de Ciencias de la Educación, de carácter regional, como instituciones para la investigación educativa y para la formación del profesorado, e incluso en oposición, si exceptuamos algunos casos ejemplares.

Rev. Diálogo Educ., Curitiba, v. 9, n. 27, p. 215-248, maio/ago. 2009 
La manifestación más singular, quizás, de ese espíritu crítico y utópico la encontramos en la constitución de numerosos pequeños colectivos de profesores para atender al cambio pedagógico y didáctico, aunque pedagogía, política y sindicalismo caminaron en aquellos momentos tan juntos y entremezclados que a menudo se interfirieron negativamente. Poco a poco y paulatinamente se iría abriendo paso a lo largo de los años setenta y ochenta una nueva cultura empírica entre un sector significativo del profesorado en toda la geografía española:

Hasta entrada la década de los ochenta, un sector importante del profesorado dedicaba cierto tiempo - en principio por medio de debates en sus zonas respectivas o en las revis-tas especializadas y, posteriormen-te, en el seno de las asociaciones de profesores y en los cursos de las escuelas de verano - a analizar la importancia de incorporar al aula ciertas técnicas pedagógicas y adherirse a algu-nas tendencias que le caracterizarían como pro-fesor o profesora "progresista». Nos referimos a tendencias (las diferencias terminológicas en-tre «sistemas», «métodos», «técnicas», se de-batían entonces en algunos ámbitos universi-tarios) que suponían reflexiones pedagógicas y estrategias metodológicas variadas: Decroly, Montessori, Freinet sobre todo, y secundaria-mente Ferrer, Freire, Don Milani (Barbiana), Neill...

También ciertas lecturas del campo más sociológico, sin intenciones metodológicas claras, influían en estos profesores: Illich, Reimer, Suchodolski, Baudelot, Establet, Mendel, Vogt, Goodman, Oury... que creaban opinión y pro-piciaban debates, y a veces paradojas por la mezcolanza de tendencias, sobre la «verdade-ra» función de la escuela.

Posteriormente irrumpió con fuerza en nuestro país la psicología de la educación y apare-ció, sobre todo, la pedagogía o didáctica ope-ratoria basada en las teorías psicológicas de Jean Piaget. Y ya muy al final de la década de los ochenta se introdujeron en el ámbito de la práctica educativa las teorías psicológicas de-sarrolladas por Ausubel, Vygotski, Bruner, Luria, Novak... En el ámbito académico, aunque no con mucha anterioridad, ya eran entonces objeto de estudio. (IMBERNÓN, 1991, p. 48).

Luego de varios años de titubeo en la acción política oficial, y en medio de una fuerte inestabilidad, con las elecciones parlamentarias de 1982 llegaba el Partido Socialista Obrero Español a la gobernación de un Estado, que había

Rev. Diálogo Educ., Curitiba, v. 9, n. 27, p. 215-248, maio/ago. 2009 
comenzado también a descentralizarse, a través de la constitución de varios parlamentos y gobiernos regionales (Cataluña, Euskadi y Galicia). Mediante la acción de gobierno, particularmente desarrollada entre 1983 y 1990, se consolidaría definitivamente un sistema educativo democrático y descentralizado y con claves de modernización, algunas de ellas sostenidas por el impulso original de los movimientos sociales y profesionales a los que hemos hecho referencia.

Detectadas las limitaciones de la más tradicional cultura y códigos escolares, crecientemente confrontados con otras agencias de socialización, en particular los medios de comunicación audiovisual, se hacía necesario revisar los contenidos escolares, como parte significativa de la cultura escolar, así como los modos y procesos didácticos de su asimilación y dominio. Se abrieron por esto espacios a la reflexión sobre lo que deberían ser los currículums y sus fuentes de fundamentación y sobre las propias características logocéntricas, psicocéntricas o socio-céntricas de los programas escolares, lo que llevó a emprender un prolijo camino de estudio, de debate y de formación dificultosamente seguido por los sectores innovadores del profesorado, mientras era desconsiderado por la gran mayoría sociológica e incluso por aquellas Administraciones Autonómicas que se mantenían fuera de la órbita socialdemócrata.

Bajo estas preocupaciones de reforma curricular podríamos entender la promoción de programas experimentales formulados desde el Ministerio de Educación y desde la Generalitat de Cataluña, la creación de los Círculos de Estudio e Intercambio para la Renovación Educativa (CEIRES, 1983) y sobre todo de los Centros de Profesores o CEPs (1984), al servicio de la formación en servicio de los profesores y de la innovación didáctica y metodológica, una vez suprimido el Instituto Nacional de Ciencias de la Educación (1981) y restringidos en la práctica los ICEs al ámbito universitario y a la mal valorada y pobre formación inicial pedagógica del profesorado de educación secundaria.

En esta dirección habría que entender asimismo la creación en 1983 del Centro Nacional de Investigación y Documentación Educativa (CIDE), como organismo técnico que desde 1986 asume cometidos sobre la evaluación del sistema educativo. El CIDE, que será responsable de la Revista de Educación, dará su apoyo a la edición de diversas obras y textos de referencia en torno al conocimiento pedagógico y sobre la educación elaborado en los campos de la psicología, la sociología y la antropología de la educación, desde un horizonte crítico, lo que facilitará el conocimiento entre nosotros de las posiciones y aplicaciones en la enseñanza de las tesis de Vigotsky, de los debates en torno al constructivismo y la escuela, de la investigación-acción y de los enfoques propios de la sociología educativa crítica, a través de una serie de obras más citadas que leídas en el marco de las cada vez más abundantes Escuelas de Verano. En esta orientación y con la preocupación por formar un profesorado con capacidad

Rev. Diálogo Educ., Curitiba, v. 9, n. 27, p. 215-248, maio/ago. 2009 
reflexiva y teórica para el logro de una profesionalidad fundada, hay que inscribir igualmente la presencia, entre otros, de los textos de L. Stenhouse, de J. Elliott, de D. A. Shön y de K. M. Zeichner.

La búsqueda de la renovación pedagógica y profesional docente fue, creemos, uno de los elementos más visibles de estos momentos en cuanto al desarrollo educativo. Con tal intencionalidad, el Ministerio de Educación abría en 1984 la fase de la experimentación curricular. Las publicaciones y los documentos de trabajo oficiales promueven, al menos formalmente, los procesos de investigación-acción para la formación del profesorado y las perspectivas constructivistas en cuanto a las cuestiones relacionadas con el aprendizaje cognitivo y el desarrollo, procurando promover una tensión creativa entre la teoría y la práctica educativa, si bien el enfoque utilizado dejaba en un segundo plano el análisis y las variables sociológicas globales de la problemática escolar, y así también el debate sobre las finalidades educativas.

En este contexto próximo, finalmente en 1990 el Ministerio de Educación daba curso a una nueva y comprometida reforma del sistema educativo español, mediante la Ley de Ordenación General del Sistema Educativo (LOGSE), para comenzar a aplicarse en 1991, con un horizonte de desarrollo abierto hasta el 2002. A través de esta Ley se promovía la elevación de la obligatoriedad escolar hasta los 16 años, incluyendo en ella un ciclo unificado y comprensivo de cuatro cursos, entre los 12 y los 16 años. Su acentuación de una orientación psicológica en cuanto al diseño de los currículos, con reducción de los planos sociológicos, por una parte, su lenguaje técnico alejado del conocimiento empírico de los sectores renovadores, la animadversión que encontró entre el profesorado de educación secundaria, que veía minorado su status social y que no asumía tampoco los presupuestos didácticos, ni el discurso del profesor investigador y reflexivo, por otra, produjeron, sin embargo, a lo largo de los noventa una importante disintonía, que conduciría a una reducida eficacia de la Ley, en contra de todo lo esperado.

Con la LOGSE, a pesar de ello, se actualizaban los currículums de educación infantil y de educación primaria; se introducían los contenidos educativos transversales; se constituía una única etapa formativa de carácter comprensivo entre los 12 y los 16 años, haciéndose gratuita y reafirmando su obligatoriedad; la formación profesional situada a partir de los 16 años adquiriría entidad propia; se regulaba la evaluación como un seguimiento continuo e integral del desarrollo del alumno, extendiéndose además también al profesorado, a los centros y a la propia Administración; se reestructuraba la organización especializada de los bachilleratos; se abría la puerta a una nueva y superior consideración de la formación requerida para el ejercicio docente, y se procedía a una importante revisión de todos los contenidos de aprendizaje y formativos y de los propios criterios sobre los aprendizajes.

Rev. Diálogo Educ., Curitiba, v. 9, n. 27, p. 215-248, maio/ago. 2009 
Entre los sectores y grupos de renovación pedagógica que con más consciencia se adhirieron a un pensamiento crítico se mantuvo, entretanto, la defensa de una escuela alimentada por la orientación de las pedagogías críticas, por las tesis de la investigación-acción como estrategia al servicio de la profesionalidad docente, por los principios de la cooperación y de la participación en el diseño y selección del currículum, en la gestión del centro y en todos los asuntos de la vida diaria, y por la constante inserción y apertura hacia el entorno, hacia sus oportunidades, pero también hacia sus problemas, tratando de intervenir desde lo específico pedagógico, en su resolución, entendiendo todo esto como la renovación pedagógica y como modelo de escuela pública, integradora, democrática, participativa y laica.

Mientras, en el transcurso de los noventa bajo la influencia de la globalización y del pensamiento neo-liberal se deterioraron las promesas de las transformaciones democráticas, incidiendo esto, así mismo, en la vida de las comunidades escolares; en estas circunstancias, las llamadas a la deseable calidad educativa comenzaban a poner un marcado acento en el rendimiento escolar de los centros y de los alumnos, aunque sin hacer referencia en la misma medida a las desiguales situaciones de los educandos y a las específicas necesidades de formación, sólo atendidas desde la narrativa de la educación compensatoria. En esta dirección es preciso referirse a la aprobación de una nueva ley, que complementaba algunos aspectos y, sobre todo, redefinía otros de la LOGSE; nos referimos a la Ley Orgánica de Participación, Evaluación y Gobierno de los centros educativos (LOPEGCE), aprobada en noviembre de 1995, con la opinión contraria de las organizaciones sindicales de clase del profesorado y del conjunto de los movimientos de renovación pedagógica porque, aún aceptando algunas correcciones, había otras consideradas contrarias a lo que debería ser una escuela pública participativa y comunitaria, que ahora aparecían inspiradas por posiciones de racionalidad instrumental, tecnocráticas y neo-liberales, aunque con ropaje terminológico aparentemente nuevo, que creaba sensación de novedad.

En estas circunstancias se producían también: la deriva burocráticoadministrativa de los Centros de Profesores, habiendo engullido lo que en otro momento había sido una vanguardia pedagógica; la asunción oficial de los presentados como "indicadores de calidad" de la OCDE, obligando al sistema educativo a guiarse por criterios de pericia técnica y academicista, desplazando al conocimiento y análisis de los significados, intereses y expectativas sociales posibles; el apagamiento de la preocupación por el desarrollo del modelo de profesor reflexivo; y el corto éxito y continuidad manifestada por el conjunto de las innovaciones, que a menudo derivaron en prácticas ritualizadas, al no llegar a modificar las concepciones, actitudes y representaciones más profundas de los

Rev. Diálogo Educ., Curitiba, v. 9, n. 27, p. 215-248, maio/ago. 2009 
profesores, o también sus resistencias. ${ }^{4}$ En este mismo marco, expresaba Fernando Hernández (1993) que se trataría de estar "imponiendo (por decreto) unas concepciones pedagógicas y unos criterios de formación (el lenguaje de la Reforma)," sustituyendo con este nuevo dudoso entramado la cultura pedagógica y las innovaciones logradas por muchos profesores.

En estas circunstancias, en 1996, y luego de tres legislaturas socialdemócratas, accedía el conservador Partido Popular a la gobernación del Estado, desde la que en 2002, lograba aprobar una nueva ley, que reformaba aspectos considerables de la LOGSE de 1990, promoviendo con más decisión el profesionalismo docente, tecnicista e instrumental, así como la eliminación de los aspectos comprensivos en la organización de los currículos, o el refuerzo de una carrera docente corporativista. Un nuevo triunfo electoral del PSOE en 2004 iba a provocar la caída de esta Ley de Calidad de la Educación de 2002, pero también la anulación completa de la LOGSE, mediante la aprobación en 2006 de la nueva Ley de Ordenación Educativa (LOE), que actualmente se mantiene en vigor: un escenario de algún modo intermedio entre lo que era la LOGSE y lo que proponía la Ley de los conservadores, ajustándose, por otra parte, a la agenda educativa internacional trazada por la OCDE, más que por la propia Unión Europea.

\section{La Revista de Educación como observatorio de debates e investigaciones internacionales sobre la formación del profesorado}

La Revista de Educación, órgano oficial del Ministerio español de Educación, de carácter cuatrimestral, que actualmente alcanza su número 345, se inscribe en el campo de la pedagogía escolar como fundamental soporte del discurso administrativo-político. En 1969 en el marco de la decidida modernización educativa española comienza a ser editada por la Secretaría General Técnica de dicho Ministerio de Educación, bajo un consejo de redacción presidido por Ricardo Díez Hochleitner y dirigido por José Blat Gimeno, incorporando en aquellos momentos también el discurso científico-técnico y una constante referencia a aquellos documentos e informes emanados de las agencias internacionales, con citación específica de los procedentes de la UNESCO, el Consejo de Europa y la OCDE. Se trata de una publicación de corte académico y con importante especialización, sobre todo desde los primeros años ochenta del siglo XX, siendo sometida a rigurosos controles de calidad como publicación científica, que se halla indexada en las más prestigiosas bases de datos internacionales de ciencias sociales.

$4 \quad$ Relacionadas con los más arraigados usos docentes tradicionales.

Rev. Diálogo Educ., Curitiba, v. 9, n. 27, p. 215-248, maio/ago. 2009 
En la Revista de Educación la cuestión de la formación del profesorado, como también el estatuto docente disponen de una considerable atención, desde los primeros años ochenta en particular, de lo que podríamos deducir su relevancia como observatorio a considerar.

En el espacio de los 36 años analizados se han localizado algo más de 100 contribuciones en torno al estatuto docente y a la formación del profesorado, con dominancia de este último tópico genérico, detectándose un período de tratamiento especialmente álgido entre los años 1982 y 1992, inclusive con más de 60 referencias. Las contribuciones entre 1969 y 1981 alcanzan una reducida cifra de 20, ocho de las cuales obedecen al número 241 de 1975, en donde monográficamente se procura trazar un inseguro balance y perspectivas en cuanto a la formación del profesorado. El monográfico no 269 de 1982 sobre formación del profesorado, construido desde los supuestos técnicos de los programas $\mathrm{P} /$ CBTE abre un tiempo de intensa atención; el número también monográfico 277 de 1985 marca un cambio de paradigma, al abrir paso a los estudios sobre pensamiento y socialización de los profesores, en relación con la formación, lo que se continúa en los números 282 y 284 de 1987; la formación del profesorado es motivo de atención continuada también entre los años 1995 y 1999, dedicándosele otro monográfico notable en el número 340 de 2006, a la luz de la agenda internacional trazada por la OCDE en 2004. Lo relativo a la profesión docente y a su estatuto merece la precisa atención de dos notables monográficos, el 285 de 1988 y el 306 de 1995.

En cuanto a la formación del profesorado, siempre en el campo de la pedagogía escolar y de los niveles primario y secundario del sistema escolar, las referencias que aparecen en la Revista de Educación tienen un alto contenido teórico, epistemológico y conceptual, de preferencia sobre aportaciones de orden sociológico, administrativo y político-legal, e incluyen también investigaciones empíricas. Para la ocasión hemos focalizado nuestra atención en las anteriores, seleccionando en conjunto una cuarentena en ese espacio de 36 años, si bien 17 de ellas se han publicado a lo largo de los años ochenta, década en la cual entre nosotros se produce el cambio de mirada sobre los supuestos, las tesis y las derivaciones en relación con la formación del profesorado.

Es necesario decir algo sobre la autoría: en mayor número de casos se trata de autores españoles con vinculación universitaria a las ciencias de la educación, o con vinculación al propio Ministerio de Educación, pero también hay un número notable de investigadores o ingleses o norteamericanos; las referencias son crecientemente anglosajónicas.

Este aumento de la preocupación por la formación del profesorado es parejo con la mayor preocupación internacional. Hay que señalar, en este sentido, que las contradicciones estructurales que se manifiestan en los sistemas educativos

Rev. Diálogo Educ., Curitiba, v. 9, n. 27, p. 215-248, maio/ago. 2009 
también en España, como consecuencias de la expansión y desarrollo de estos sistemas, a causa de una conjunción de situaciones y supuestos como fueron/son la necesidad de socialización de los ciudadanos, la de atender a demandas sociales alfabetizadoras y escolarizadoras, las expectativas y necesidades que se registran en el campo económico y en los mercados laborales, el empuje de la "teoría del capital humano", los procesos de descolonización/de modernización social, entre otros, obligaron a los responsables políticos y a las agencias internacionales a abordar con mayor detenimiento todo lo relativo a los programas de formación del profesorado. A lo largo de los años sesenta y setenta así se puso de manifiesto en diversos documentos. A título de ejemplo citamos:

- 1974. OCDE: Tendances nouvelles de la formation et des tâches des enseignants. Rapport de synthèse. París.

- 1975. UNESCO: Recomendación sobre la evolución del papel del personal docente y consecuencias de esa evolución en la formación profesional previa y en servicio, XXXV Conferencia Internacional de Educación. Ginebra.

- 1975. OCDE: Les institutións responsables de la formation des enseignants. Problèmes et tendances nouvelles dans quelques pays européens et en Amérique du Nord.París.

- 1976. OCDE: Tendances nouvelles de la formation et des tâches des enseignants. L'enseignant innovateur.París.

- 1979. OCDE: Teacher policies a new context.París.

Una preocupación que se hacía igualmente presente en una creciente y cada vez más relevante literatura académica, entre la que espigamos las siguientes referencias:

- 1967. RYANS, D. G. Characteristics of teachers. Their description, comparison and appraisal. Washington: American Council of Education.

- 1971. GOZZER, G. Further training of teachers. Strasbourg: Council for Cultural Cooperation.

- 1973. LYNCH, J.; PLUNKELT, H. Teacher educacion and cultural change. London: Allen and Unwin.

- $\quad$ 1973. TRAVERS, R. (Ed.). Second handbook of research on teaching. Chicago: Rand McNally Col.

- $\quad$ 1975. BURDIN, J. The changing world and its implications for teacher education. In: RYAN, K. (Ed.). Teacher education. Chicago: University of Chicago Press. $35^{\text {th }}$ ed. Yearbook of the N.S.S.E.

Rev. Diálogo Educ., Curitiba, v. 9, n. 27, p. 215-248, maio/ago. 2009 
- $\quad$ 1976. MORRISON, A.; Mc INTYRE, D. Teacher and teaching. Harmondsworth: Penguin Book.

- 1977. MIALARET, G. La formation des enseignants. Paris: PUF. GOBLE, N. M.; PORTER, J. F. The changing role of the teacher. Paris: Unesco.

Desde mediados de los años 70 la literatura académica y los informes internacionales alrededor de la identidad profesional, la diversificación, los retos de formación inicial y a lo largo de la vida profesional de los profesores y sobre su estatuto no ha dejado de crecer, sea en Europa, sea en Canadá, en América del Sur, en Australia y Nueva Zelanda, y en los Estados Unidos. En todo caso, la Revista de Educación nos puede servir de observatorio en lo relativo a la cuestión de la formación.

\section{Se impone la imagen del "profesor eficaz"}

El extraordinario ensanchamiento de los sistemas nacionales de educación por una parte, las transformaciones científico-tecnológicas, por otra, las importantes mutaciones culturales de todo orden, o la propia presencia de las culturas juveniles en los centros de educación, chocaban desde los primeros años sesenta del siglo XX, con lo que venían siendo los modos de ser y de estar de la mayoría de los docentes.

La formación inicial, que era en orden decreciente académica, cultural y pedagógica, o acaso también de iniciación profesional a través de algún ejercicio práctico, parecía no resultar ya adecuada para preparar las nuevas y cada vez mayores cohortes de docentes de educación primaria y de secundaria. Al respecto, se comienza a observar que se trata de una formación de muy reducido valor didáctico y profesional, y también culturalmente limitada en el caso del profesorado de educación primaria. También, se imponen otras evidencias: por una parte, la necesidad de reformar estructuralmente los propios centros de formación de profesorado, tanto para acoger a un mayor número de demandantes, como para atender a tal formación con mayor adecuación profesional, lo que hacía del caso su aproximación, sino su incorporación, a las instituciones universitarias. Por otra, la necesidad gubernamental de generar estrategias, servicios y programas técnicos de perfeccionamiento en servicio de la formación docente, incluso de modo cuasi sustitutorio de una deficiente formación inicial, a veces difícil de modificar.

La convicción sobre la necesidad de las modificaciones se refleja en la Revista de Educación a través de las contribuciones de Jacques Bousquet $(1971,1972)$ y de Torsten Husen (1971). La concepción artesanal, en la que a pie de obra se

Rev. Diálogo Educ., Curitiba, v. 9, n. 27, p. 215-248, maio/ago. 2009 
transmiten los saberes docentes curriculares, didácticos y organizativos, con su fuerte y a veces sólida carga empírica, entre los propios docentes (los "experimentados" y los noveles) es crecientemente desconsiderada como estrategia formativa. Tampoco el buen hacer podía quedar al azar, confiando en la genialidad o en la dimensión de arte alcanzada excepcionalmente. Había que afrontar, entonces, el reto de formar "buenos profesores"; ¿'en qué consiste ser un buen profesor?

Desconsiderada la perspectiva filosófica y racionalista de la pedagogía normativa se imponía la realización de estudios experimentales. Es decir, era preciso dar una base científica positiva a tal proceso de formación. Y aquí, la psicología nutriría (LUNDGREN, 1988) las primeras orientaciones, que vendrían de la mano de la psicología humanista y del conductismo.

Desde la psicología humanista y a partir de la teoría del campo psicológico formulada por Kurt Lewin (1936), que examina el comportamiento humano como un todo global, se abrían paso los conceptos de grupo y de interacción en el aprendizaje, algo a ser considerado entonces en la formación del profesorado. El buen profesor no sólo tendría el más alto nivel de conocimientos en una sociedad caracterizada por una economía del saber y la acumulación de conocimientos, ni solo una buena capacidad de autoaprendizaje, ni tampoco sería suficiente que fuese experto académico y didáctico en las disciplinas enseñadas. Debería saber ocuparse y resolver actividades y tareas de grupos e integradoras, lo que es tanto como abordar el clima socio-emocional de los grupos y clases, saber estimular la acción del grupo y de los individuos y saber distribuir tareas, llegándose a la certeza de que el acto de enseñar se componía de actividades diferenciadas, aunque interconectadas entre sí, y de que eran precisos estudios sobre la lógica y estructuración de las clases como grupos de aprendizaje, sirviéndose al efecto del modelo socio-psicológico de sistema social construido por Getzels y Herbert Thelen (1960), que analiza la escuela dentro de un sistema social mayor. Fueron, así, frecuentes los estudios sobre el clima de aula y sobre los rasgos docentes (RYANS, 1967), tal como señalaba Oliveros (1969), a fin de observar cómo sus características influían en las dinámicas de aula, si bien las evidencias de la investigación no conseguían alejarse de las evidencias empíricas.

Debido a esto, las investigaciones se dirigieron hacia los comportamientos explícitos de los profesores, para analizar cómo y en qué grado sus actuaciones podían afectar a la consecución de los objetivos cognoscitivos de aprendizaje de los estudiantes, y ser por ello funcionales, abriéndose así la puerta a la imagen del "profesor eficaz".

Inspirándose en la teoría skinneriana sobre el condicionamiento operante y la modificación de la conducta y en las propuestas conductistas de Ralp Tyler elaboradas desde Chicago con su obra Basic principles of Curriculum and Instruction (1949), en donde presenta un modelo curricular procesual

Rev. Diálogo Educ., Curitiba, v. 9, n. 27, p. 215-248, maio/ago. 2009 
comportamentalmente orientado, B. S. Bloom, el creador del movimiento de los objetivos de aprendizaje, creó un modelo de enseñanza para la Maestría o dominio (Mastery Learning), basado esencialmente en la certeza de que con procesos adecuados de enseñanza individualizada, el 95\% de los alumnos podía alcanzar el "dominio" de las capacidades y conocimientos fundamentales, sirviéndose para esto de una "taxonomía (psicológica) de objetivos cognitivos" (1956), es decir, un sistema ordenado para la clasificación y jerarquización de los objetivos, que concreta en cada materia las operaciones instruccionales básicas sobre las que se organizan jerárquicamente las demás operaciones que van siguiendo, de acuerdo con la complejidad creciente de los procesos cognitivos, para poder dar cumplimiento a una amplia taxonomía de objetivos generales, específicos y comportamentales, evaluados todos en su consecución de un modo detenido.

Así, los profesores tendrían a su disposición una estrategia, libre de valores, para la organización sistemática de los procesos y momentos de aprendizaje, con márgenes para alguna creatividad y capacidad dinámica personal. Un modelo eficientista y tecnicista y un sistema pedagógico que permitía el control de los procesos de aprendizaje en cuanto al recorrido a realizar para alcanzar el saber, repleto de esquematismo y de simplificaciones, preocupado por la racionalización de los procedimientos y por una concepción rentable de la calidad de la educación, que conectaba íntimamente con la visión funcionalista de la educación en el terreno político, en el económico y en el sociológico. Un modelo asentado sobre el paradigma de la gestión empresarial (ROBBITT, 1913) y sobre el taylorismo, que conducía a la apreciación del conocimiento de acuerdo con su valor en el mercado, y desconocía la cuestión de las finalidades.

En el conjunto de esta orientación, la Didáctica se identifica con la Tecnología; es decir, con una forma precisa de programación y evaluación que ofrece la "garantía" de la precisión y la claridad tecnológica y la "seguridad" de la eficacia y la eficiencia, al servicio de una perspectiva tecnocrática del desarrollo social, sin cuestionamientos epistemológicos ni ideológicos, en conexión con el Management Sciencie Movement. Una perspectiva de racionalidad técnica, a la que contribuyeron destacadamente R. Tyler, Bloom, Mager ( con su formulación operativa de objetivos didácticos), Gagné, Popham, Taba o De Landsheere.

La propuesta, dada su utilidad en cuanto a la modificación de conductas, ha alcanzado un considerable éxito y utilización, pero también ha recibido fuertes críticas por parte de quienes piensan que el razonamiento, el lenguaje y las emociones ejercen una función importante, no considerada, en la génesis de las conductas.

Bajo esta orientación, que enlaza con la lógica tecnocrática que informaba los proyectos funcionalistas de ingeniería social, se contemplaba igualmente la cuestión de la docencia como un problema de ingeniería humana,

Rev. Diálogo Educ., Curitiba, v. 9, n. 27, p. 215-248, maio/ago. 2009 
una vez que se distinguen los planos de la investigación y la proposición, por una parte, y el de la aplicación, por otra, situando aquí a los profesores como receptores y transmisores de normas institucionales y de un conocimiento exento de valores y legitimado, porque lo que el profesional o técnico aplica como producto, según las situaciones, fue previamente elaborado, graduado y comprobado, generándose una jerarquía profesional estratificada como consecuencia del grado de especialización docente, y de dominio de determinadas competencias o habilidades.

En esta perspectiva, la formación inicial y en servicio del profesorado será contemplada desde la técnica de la programación por objetivos, de modo prescriptivo, lineal y apriorístico. Por un tiempo esta perspectiva se impone, y con ella el estudio de las competencias, funciones o papeles del profesor, "concebidas, primero como cualidades y habilidades aisladas correlacionadas con la eficiencia profesional posterior, pero más tarde, concebidas como modelos de conducta complejos y unitarios, que suponen la integración de cualidades personales, habilidades y actitudes adquiridas, capacidad de interacción social y efectividad en el rendimiento" (OLIVEROS, 1975).

Lo que se explicitó en programas como el PBTE (Performance-Based Teacher Education) para la planificación concreta, articulada y procesual, la evaluación y la modificación de conductas de interacción docente (HOUSTON, 1972), también denominado CBTE (Competency-Based Teacher Education), y en la "microenseñanza", para provocar en este caso el aprendizaje por parte de los docentes o de futuros docentes de determinados diseños instructivos, con el fundamental apoyo de una metodología e instrumentación tecnológica multimedia, a costa en todo caso de la fragmentación en la formación docente.

La Revista de Pedagogía se hace eco de este paradigma al menos en 1975, a través del número monográfico 241, con aportaciones sobre el programa CBTE (DICKSON, 1975), la microenseñanza (ALLEN, 1975) y el perfeccionamiento del profesorado en ejercicio (ESCUDERO; FERNÁNDEZ URÍA, 1975), entre otros, que se corresponden con las orientaciones que para la formación continuada del profesorado promueve el Ministerio de Educación, a través de la Red INCIE -Institutos (regionales) de Ciencias de la Educación, sobre los que descansará una intensa programación de cursos de reciclaje anclada en la pedagogía por objetivos, que se mantendrá aún en los primeros años ochenta.

En 1982, Arturo de la Orden, uno de los más legitimados expertos del momento, afirmará que en España la formación y el perfeccionamiento del profesorado "distaban de apoyarse en evidencias contrastadas", debiendo ser preparados los docentes como "profesionales", esto es, "con competencias específicas que solo pueden adquirirse mediante un proceso especializado, pautado y racionalizado, tal como los programas CBTE” (DE LA ORDEN, 1982), y como especialistas en enseñanza y aprendizaje, "apoyados en un cuerpo de

Rev. Diálogo Educ., Curitiba, v. 9, n. 27, p. 215-248, maio/ago. 2009 
conocimientos teóricos, que le configuran como el único competente y responsable para prestar el relevante servicio educativo a la sociedad".

La búsqueda de la eficiencia profesional se encuentra igualmente presente en aportaciones aparecidas en 1980 en la Revista de Educación sobre la enseñanza programada y asistida por ordenador, y sobre tecnología educativa, examinada la cuestión desde la psicología del aprendizaje, la teoría de la comunicación y la teoría de sistemas, depositando en todo ello una importante confianza, si bien alertado del riesgo de la baja calidad técnica de los materiales didácticos, o de que los técnicos se considerasen pedagogos.

A pesar de reclamar la eficiencia y la especialización profesional y de asumir la elaboración de competencias como fundamento para el diseño del curriculum de la formación del profesorado (BERNAT, 1982), con un criterio de unión de teoría y práctica ${ }^{5}$ para la profesionalización docente, percibe, sin embargo, Gimeno Sacristán (1982) que "la profesionalidad es un constructo complejo", ya que son exigibles destrezas epistemológicas para poder intervenir en situaciones concretas y reales, alejadas de una mecanización rutinaria de destrezas, tal como ya se avisaba, anota Gimeno, por parte de diversos estudiosos norteamericanos, teniendo además en cuenta la ampliación y diversificación de las metas educativas de las escuelas y la diversificación de los posibles roles y funciones de los docentes, con la correspondiente diversidad de modelos formativos.

Se estaba llegando a la conclusión de que la formación técnica por competencias, apriorística y lineal, tampoco acertaba a responder a la necesidad de que los profesores alcanzasen las oportunas destrezas epistemológicas para intervenir en las situaciones concretas, dado el constatado carácter singular de toda práctica didáctica, en entornos escolares ecológicos diversos. Se estaba llegando a la convicción de ser muy limitada la perspectiva de construcción de la identidad docente centrada en el dominio especializado y didáctico de una disciplina académica.

$\mathrm{Al}$ respecto, las numerosas investigaciones empíricas realizadas en los escenarios anglosajones acerca de cómo debía ser el comportamiento "profesional" de los profesores, poniendo el énfasis tanto en la actuación y en el rendimiento observable en el alumnado, como en los amplios listados de competencias o capacidades explícitas a adquirir por los docentes a través de los procesos formativos específicos, no se traducían luego en una adecuada resolución de conductas en las prácticas concretas en la medida esperada.

Cierto que cada acto docente podría ser analizado como un conglomerado de destrezas compuesto de conductas observables, que al ser identificadas podrían ser evaluadas y modificadas de ser oportuno, aunque resultaba

Bernat Montesinos hace aquí mención pionera, entre nosotros, al trabajo de ZEICHNER, 1980. En el Zeichner se refiere a los riesgos de la socialización de los nuevos profesores en el seno de escuelas conservadoras.

Rev. Diálogo Educ., Curitiba, v. 9, n. 27, p. 215-248, maio/ago. 2009 
mecanicista la creencia en la posibilidad de sumar y de yuxtaponer microconductas, para con ellas componer comportamientos más complejos, pero no menos cierta resultaba ser la diversificación de funciones de los docentes en los centros educativos y la variabilidad de las situaciones específicas, ante lo que difícilmente respondía el modelo del "profesor eficaz", con esa separación entre lo experimental y los contextos situados.

A lo largo de los años setenta otras evidencias ponían igualmente de manifiesto que a pesar de ser formados los profesores en el uso de la programación por objetivos, según los esquemas de Bloom u otros, esto no se traducía como se esperaba en el plano práctico, observándose, al contrario, que los profesores se manifestaban reacios muy frecuentemente a modificar sus rutinas.

La cuestión invitó a interrogarse por cómo los profesores piensan y sobre cómo y por qué toman decisiones, procurando comprender la racionalidad ahí presente y cómo su comportamiento está dirigido por sus pensamientos y juicios.

\section{E1 "profesor reflexivo" como nuevo paradigma}

Las evidencias acumuladas pusieron, así, en crisis el modelo del "profesor eficaz" sostenido en los supuestos curriculares tylerianos.

La pretensión de generar teorías prescriptivas desde el paradigma proceso-producto no consideraba, sostiene Pérez Gómez (1987, p. 203) ni las variables mediacionales, ni el mundo de los significados presentes en el pensamiento de los profesores, ni por ello la naturaleza singular del intercambio en cada espacio ecológico que cada clase o grupo de aprendizaje representa, al descuidar la toma de consideración de los concretos y específicos contextos socio-culturales.

Se puso igualmente de manifiesto que también el aprendizaje por competencias inspirado desde claves conductistas, sostiene el mismo Pérez Gómez (2008, p. 77), "ignora la conexión completa e interactiva entre tareas, los atributos mentales que subyacen a los comportamientos, el carácter siempre polisémico de los significados, y la importancia decisiva de los aspectos éticos e interpersonales", al excluir de su consideración los aspectos de compleja evaluación, como son las disposiciones morales.

Por lo dicho, el aprendizaje por competencias tampoco garantizaba un aprendizaje comprensivo, reflexivo, conflictivo incluso. Se trataría de programas de formación del profesorado que contribuían a legitimar la ideología del "profesionalismo" a través de categorías relacionadas con competencia, rendimiento y éxito, "eludiendo, como expresó Giroux en las páginas de la Revista de Educación (1987), las categorías macro-sociales que revelan cómo las estructuras económicas y políticas efectúan el control social influyendo en la ideología y la

Rev. Diálogo Educ., Curitiba, v. 9, n. 27, p. 215-248, maio/ago. 2009 
cultura que forman parte del tejido cotidiano de estos programas", en lugar de favorecer la comprensión de los procesos cognitivos y un mejor aprendizaje. Sería preciso, indicaba Giroux, no seguir manteniendo una noción despolitizada de la cultura, que en cuanto a la formación del profesorado obedecía a supuestos encuadrables en la lógica tecnocrática.

Por lo cual, se imponía en estos programas abordar la formación de capacidades y estrategias docentes de carácter global y en contextos situados, centrándose en los mismos profesores y en sus tareas cotidianas, y desde ahí, con la participación de los implicados y comprendiendo la racionalidad de los actores, llevar adelante la construcción de identidades profesionales complejas, siendo conscientes de que la acción educativa institucional en una sociedad democrática exige la ampliación de la acción profesional, para poder responder a retos profesionales en escenarios también más complejos. Es lo que se ha convenido en señalar como la formación de una profesionalidad reflexiva, con estrategias específicas, sea que hablemos de formación inicial o de la formación en servicio, las dos modalidades conectadas entre sí y obedeciendo a una misma filosofía.

En esta dirección fueron cobrando vigor a la hora de establecer los parámetros a considerar múltiples investigaciones y propuestas conclusivas derivadas en torno a: el estudio de los contextos de aula; el conocimiento práctico y el pensamiento de los profesores, es decir, cómo se adquiere, configura y usa el conocimiento del profesor; las actitudes; los procesos cognitivos y las conductas docentes (el laboratorio mental de los profesores); la socialización de saberes y prácticas y la inserción en el oficio docente, con su detenimiento en las llamadas prácticas de formación; los profesores como investigadores; las innovaciones centradas en las escuelas; los aspectos morales, ideológicos y políticos en la formación de los docentes o también los significados y las representaciones.

Algo que, por otra parte, venía acompañando de una considerable revisión de la teoría curricular tyleriana, y de importantes debates en torno a la sociología de la educación y del conocimiento, sostenidos, desde el estrucutralismo marxista, desde corrientes neo-marxistas, desde algunas posiciones posestructuralistas, desde los enfoques etnometodológicos, y desde aportaciones postmodernistas. Max Weber con sus conceptos de dominación y de legitimación, Manheim con sus aportaciones a la sociología del conocimiento, Bourdieu con su arqueología de los saberes y con su teoría de la reproducción, Althussser con su teorización sobre la educación y los aparatos ideológicos de Estado, las tesis de Berger y de Luckmann sobre la construcción social de la realidad, el estudio de Bowles y Gintis sobre la escuela capitalista en América, las aportaciones de Basil Bernstein sobre la sociología de la transmisión cultural y sobre los códigos sociolingüísticos que regulan la comunicación, la formulación del constructo cultura escolar, Michel Young con la nueva sociología del currículum, señalándolo

Rev. Diálogo Educ., Curitiba, v. 9, n. 27, p. 215-248, maio/ago. 2009 
como uno de los mecanismos de distribución social del conocimiento desde intereses y posiciones de poder clasistas, o diversas reflexiones procedentes de destacados pensadores de la Escuela de Frankfurt, venían, en conjunto, a componer un tamizado despliegue de miradas, que alimentaron la construcción de puntos de vista fundamentalmente fenomenológicos, interpretativos y socio-críticos, desde los que se comenzaron a abordar problemáticamente los contenidos y las prácticas (Willis, Woods, Apple, Anyon, Kemmis, Giroux, Goodson), que tienen lugar en las escuelas, influyendo, sin duda, y de distinto modo en la percepción de los profesores y en las formulaciones sobre su oportuna formación.

En esta revisión, es del caso hacer referencia también a algunas de las propuestas didácticas constructivistas, a las aportaciones de la psicología del procesamiento de la información y de la psicología cognitiva, por aventurar la dimensión procesual e integrada de la arquitectura del aprendizaje, lo que invitaba a construir la imagen de profesores investigadores en la acción, como, igualmente, a las aportaciones cognitivas referidas al "pensamiento metacognitivo", desde donde se procedió a la apertura de indagaciones sobre el pensamiento de los profesores, las teorías implícitas, negadoras de cualquier formulación lineal, y la conformación del conocimiento práctico, con estudios como los de Shulman (1975), revisados por López Ruíz (2000) en la Revista de Educación, o los de R. Shavelson (1983).

Aquí hay que situar los modelos curriculares de solución de problemas que elaboran Stenhouse y John Elliott en Inglaterrra, o la denominada "reconceptualización curricular", encaminada a la construcción curricular crítica, como perspectiva reconstructiva y transformadora del currículo que, como ha señalado Pérez Gómez (1987), subraya el carácter singular de toda práctica didáctica y centra su atención en el pensamiento del profesor como factor de mediación entre la teoría y la práctica, lo que obligaría a una reconceptualización en cuanto a la formación de los profesores, a fin de revisar la estructura conceptual curricular y los métodos de aprendizaje para tal formación, a fin de hacerlos coherentes con la propuesta del profesor reflexivo y los escenarios de problematización formadora, al entender, en palabras de Doyle (1985), que "la investigación sobre los contextos de aula define un aspecto central del conocimiento básico para la formulación de políticas y programas en formación de profesorado."

Los profesores debían ser considerados agentes activos y creadores como intérpretes de pensamiento y prácticas de educación. Es lo que afirmaron, entre otros, Schön (1983) y Zeichner (1983), a la par que Stenhouse (1975) ya lo había sugerido. En una orientación en la que posteriormente alcanzarían también notoriedad internacional Fullan y Hargreaves (1992).

Esta perspectiva del profesor reflexivo, o también del pensamiento de los profesores, se hizo presente de modo más evidente en la Revista de Educación a través de un fundamental trabajo publicado por José Contreras (1985), quien se

Rev. Diálogo Educ., Curitiba, v. 9, n. 27, p. 215-248, maio/ago. 2009 
refiere como uno de los detonantes de esta orientación a los estudios realizados por la psicología del procesamiento de la información y su aplicación a diferentes tareas humanas. Contreras alude igualmente a los tipos de racionalidad activados durante la enseñanza práctica y la interactiva, y al hecho de que los procesos psicológicos básicos utilizados por los profesores debían ser enmarcados en tres contextos, el psicológico, el ecológico y el social, haciendo una presentación de los estudios e investigaciones más relevantes al respecto, para finalmente adoptar una posición crítica acerca del conservadurismo existente en los presupuestos adoptados en gran parte de la investigación por no situarse en el marco de un modelo ecológico de aula, al tiempo de sugerir lo que deberían ser las líneas más promisorias en una orientación que, sin duda, debía ser continuada.

En este mismo número de Revista de Educación se publicaban valiosas contribuciones: de Doyle (1985) sobre los contextos de aula y la política de formación del profesorado, de Stenhouse (1985), y de Zeichner (1985), en este caso sobre la socialización de los profesores, asunto sobre el que también Contreras se manifestará (1987).

Zeichner volverá a aparecer poco después (1987) señalando al respecto del paradigma las siguientes apreciaciones:

- la noción de "enseñanza reflexiva" se basa principalmente, aunque no exclusivamente, en la obra de Dewey Cómopensamos (1904, revisada en 1933);

- las prácticas de formación para profesores noveles deben contribuir a suscitar interrogantes críticos sobre la escuela;

- múltiples investigaciones sobre las forma de razonar de los profesores ponen de manifiesto su más común y generalizado "conservadurismo reflexivo", al revelar que no parecen ser especialmente reflexivos o analíticos sobre su trabajo;

- $\quad$ es preciso que los profesores razonen de forma crítica y que la dimensión moral forme parte de la formación del profesorado, entre otros motivos porque las escuelas no deben ser medios de perpetuación de las desigualdades sociales.

El pensamiento de los profesores mereció la atención de Pérez Gómez también en 1987 en la Revista de Educación, en el importante número 284 dedicado monográficamente a la formación del profesorado, del que, así mismo, queremos mencionar las contribuciones de Giroux (1987), de Terhart (1987), de Gimeno (1987) y de Pedro Cañal y Rafael Porlán (1987).

En 1988 la Revista acogió una contribución de Ernest House (1988) en la que éste hablaba de la reflexividad como una "megacompetencia" del perfil

Rev. Diálogo Educ., Curitiba, v. 9, n. 27, p. 215-248, maio/ago. 2009 
docente, al tiempo de señalar el centro escolar como marco adecuado para el desarrollo de una cultura profesional colaborativa; una práctica innovadora deseable para el desarrollo de los profesores y de los centros.

Otras aportaciones sucesivas fueron las de Barquin (1991, 1995), de Villar Angulo (1994), de Escudero Muñoz (1998) y de Juan Yanes (1998); Escudero afirma aquí que la formación continuada o desarrollo profesional, "una construcción social y política", debiera ser un permanente acompañamiento de la función docente, que implica procesos y contenidos de aprendizaje diversos, a través de diversas estrategias; Yanes, por su parte, se manifestaba en contra de las concepciones técnicas imperantes por "alejar al profesorado de una profesionalidad reflexiva", haciendo notar, en contraposición a tales concepciones lo que habían representado en España los Movimientos de Renovación Pedagógica.

En tanto que el paradigma centra los retos de los programas de formación de docentes sobre el saber práctico y su propio conocimiento hay que anotar el inicio de trabajos de investigación, como los realizados por Oliva Delgado (1995) y Sánchez García (1995), sobre el conocimiento observado en los profesores de educación infantil y en los de matemáticas, respectivamente.

Si como con frecuencia se dice una imagen vale más que mil palabras, haremos notar que en el terreno de los hechos políticos, la formación inicial del profesorado de niveles no universitarios en España no se modificó sustancialmente ante la presencia, bien del paradigma del profesor eficaz, o bien del referido al profesor reflexivo, al imperar sobre todo una perspectiva más tradicional, culturalista y generalista, aunque si de modo muy notable, al menos en las pretensiones, lo hicieron los servicios y programas para la formación continuada del profesorado en servicio. En 1969 se ponían en marcha los Institutos de Ciencias de la Educación, una docena de ellos, en toda España con la responsabilidad, bajo programación centralizada, de llevar a cabo tal formación, desde la mirada y el modelo del "profesor eficaz", y aún la esquemática formación inicial ("capacitación pedagógica": tres meses de cursos y 50 horas de "prácticas") de los aspirantes a profesores de educación secundaria. Hablamos de instituciones que hasta los primeros años ochenta canalizaron muy numerosos cursos bajo el horizonte de la pedagogía por objetivos.

Sin embargo, desde mediados de los años ochenta, en sintonía con las orientaciones anglosajonas de la época y también en un contexto de joven democracia y de reciente inicio de gobierno socialdemócrata, la formación continuada del profesorado comenzará a ser realizada desde los Centros de Profesores ${ }^{6}$, una estructura descentralizada (más de 100 centros en toda España) y con la participación

6 Los Regional Service Centers americanos o sobre todo los Teachers Centers ingleses, concebidos como espacios regionales de cooperación, en los que colaboran grupos de profesores a través de una formación en común, los intercambios de experiencias e innovaciones, se manifestaron como una estrategia adecuada para promover las reformas educativas con la colaboración docente.

Rev. Diálogo Educ., Curitiba, v. 9, n. 27, p. 215-248, maio/ago. 2009 
programática de los docentes y de los centros, aunque la bondad de la medida haya de ser matizada, a través de la observación de tales centros a lo largo de veinte años. A través de ellos se intentará organizar, realizar e incluso evaluar en los centros escolares circunscritos a cada Centro de Profesores la puesta en marcha de las reformas educativas, teniendo en cuenta las necesidades y las dificultades de los profesores y de las escuelas, en el marco de las directrices curriculares generales autonómicas y estatales, además de llevar a cabo la planificación parcial y la operativización de las actividades de perfeccionamiento del profesorado, una parte de ellas realizadas en los propios centros interesados, y de promover la información, la cooperación y el intercambio entre los profesores y los centros adscritos a cada Centro de Profesores. Obedeciendo, sin duda, al paradigma del "profesor reflexivo".

Era la filosofía que presidía la creación de los CEPs (Centros de Profesores de España) por Real Decreto 2112 de 1984, pretendiendo conciliar la iniciativa autónoma del profesorado desarrollada a través de los Movimientos de Renovación Pedagógica a lo largo de los años setenta y primeros ochenta con la preocupación administrativa por disponer de unos programas estables de formación del profesorado y de desarrollo profesional, acordes también con los propósitos de reforma política de la educación. Sin embargo, tales propósitos en pequeña medida se llevaron a la práctica, cayendo en la burocratización y en la promoción de un exceso de "cursillos" de formación, con reducida conexión con las necesidades sentidas por el profesorado, según valoración de Barquin (1995), que por ello urgía, como Escudero (1998), un reexamen y replanteamiento de estos Centros, con una revisión igualmente de la formación y funciones del cuadro de formadores de cada Centro, a fin de que su acción fuese, como pedía Carlos Marcelo (1997), mucho menos de gestión burocrática o de asesoramiento dirigido a la implantación, para ser, en cambio, de asesoramiento orientado al desarrollo.

En todo caso, en estos momentos últimos de los pasados años noventa, los técnicos del nuevo gobierno conservador español procedían a cerrar esta orientación formativa del "profesor reflexivo"; bajo una perspectiva económica y política sostenida por recetas neo-liberales lo que se imponía ahora era la "carrera profesional docente" en lugar del discurso del "desarrollo profesional" y la "profesionalización en la dirección de los centros escolares".

A pesar de que tanto en el caso español, según venimos de ver, como a escala internacional, constata la literatura académica una incierta e insegura traducción del paradigma del profesor reflexivo en las políticas escolares y de formación del profesorado, hay que señalar, sin embargo, que el ámbito de investigación alrededor de este modelo experimentó un constante desarrollo internacional, influyendo con ello en la presencia y tratamiento en los diversos sistemas educativos de asuntos como las discriminaciones sociales, las innovaciones, las nuevas tecnologías y su impacto socio-cultural, la identidad profesional, la

Rev. Diálogo Educ., Curitiba, v. 9, n. 27, p. 215-248, maio/ago. 2009 
formación de los profesores noveles, el malestar docente, o las historias de vida de los profesores, en torno siempre al capítulo de la formación docente.

François Tochon (2000), desde la School of Education de la Universidad de Wisconsin señala, por su parte, que el paradigma ha adquirido centralidad y amplitud, pero que muestra síntomas de fragmentación; estaríamos ante una hegemonía conceptual a punto, paradójicamente, de ser recuperada gubernamentalmente, a través de una tentativa reduccionista, al querer homogeneizar desde el exterior el pensamiento educativo de los profesores y de evaluar, así, sus competencias profesionales, en contra de lo que ya se han manifestado en los últimos congresos de la AERA (la Asociación Americana de Investigación Educativa) posiciones favorables al mantenimiento de una "heterogeneidad conceptual que preserve la libertad de pensar de modo diferente".

\section{"Formar por competencias": ¿un nuevo modelo en la agenda educativa global?}

De igual modo que existe una publicista académica internacional sobre modelos docentes, profesionalización y profesión docente, también existe un marco propositivo internacional al que hemos aludido con anterioridad, haciendo mención a la UNESCO, la OCDE y el Consejo de Europa.

Estas proposiciones de carácter internacional se han venido intensificando en la actualidad y ello tanto por la globalización, como por el alcance de la tecnología informacional o el aumento de la conciencia sociológica relativa a nuestro planeta. Sin duda, existen fenómenos que podemos llamar de "modernización" que alcanzan a todo nuestro mundo, y entre ellos se cuenta el desarrollo educativo, hasta tal punto que se ha llegado a hablar de que "se ha producido una homogeneización mundial de la educación” (HÜFNER, 1992).

En este contexto, que es también en el de una nueva configuración capitalista internacional, el de la globalización neo-liberal, se sitúan ahora mismo la Unión Europea, la OCDE, la Organización Mundial del Comercio o el Banco Mundial, el G-7, o el G-20, que constituyen foros desde los que se viene desarrollando, como sostiene Antunes (2007, p. 425), una actuación:

[...] de proposiçao e imposiçao de tendências e coordenadas que orientan influentes formas de pensar e poderosas actuaçoes políticas de envergadura continental ou transcontinental de reestruturaçao de todo um sector de ensino e da formaçao professional ou de definiçao dos parámetros de avaliaçao, organizaçao e funcionamento dos sistemas de ensino.

Rev. Diálogo Educ., Curitiba, v. 9, n. 27, p. 215-248, maio/ago. 2009 
Es decir, estaríamos asistiendo a la constitución de una "agenda globalmente estructurada para la educación”, tal como expresó Dale (2000), como expresión de un nuevo orden educativo mundial, de naturaleza transnacional y obedeciendo al discurso capitalista neoliberal, lo que debilitaría los perfiles de los sistemas nacionales de educación, para dar curso a tendencias de desarrollo de más largo alcance y de más complejo control democrático e institucional.

Es en este contexto donde debemos referirnos al desarrollo educacional en la Unión Europea, una instancia supranacional, y al papel jugado por el Centro Internacional de Investigación Educativa (CERI) de la OCDE, y por una plataforma intergubernamental como el Proceso Bolonia iniciado en 1999, aunque podríamos también referirnos a otras agencias supranacionales.

En el contexto europeo esa agenda globalmente estructurada se expresa en el Programa de la Unión Europea "Educación y Formación en Europa 2010" (COMISIÓN EUROPEA, 2002) y en el documento Principios Comunes europeos para las competencias y cualificaciones de los profesores (COMMISION OF THE EUROPEAN COMMUNTIES, 2005), además de en el Proyecto Tuning (2003), ${ }^{7}$ al servicio de la puesta en marcha del Espacio Educativo Superior Europeo.

La Comisión Europea ha trazado un horizonte para el desarrollo educativo hasta el 2010 a fin de responder a expectativas/necesidades de desarrollo económico, tanto como mercado interior, como economía unitaria en el contexto mundial globalizado. En ese contexto, la Comisión prevé la construcción de un mercado común laboral europeo ligado al desarrollo educativo, sobre la base reguladora de un sistema de reconocimiento y de transferencia de competencias y cualificaciones, lo que incluye la cuestión de la formación del profesorado, poniendo en juego un tratamiento técnico y pragmático que puede poner en riesgo algunos de los supuestos más firmes que en el reciente pasado alimentaron el discurso de la profesionalización docente, y abrir escenarios de desregulación para la construcción del mercado laboral docente, o en todo caso de constitución de un "nuevo profesionalismo", caracterizado por la "pericia" en el trabajo, sin un suficiente y sólido trasfondo intelectual o político, restringiéndose, pues, como señala Antunes (2007, p. 452) el ámbito epistemológico de la reflexión sobre la experiencia docente y la realidad diaria.

A tales efectos de constitución de tal mercado laboral, teniendo en cuenta la caducidad de la información para la constitución del conocimiento, y también en la creencia de que en el futuro inmediato las personas llegarán a desempeñar diversos puestos laborales a lo largo de su vida laboral (precisando, por ello, un acompañamiento en su formación), desde las agencias transnacionales citadas

Tuning Educational Structures in Europe; el intento de ofrecer un modelo de diseño curricular esencial, estandrizado y eficaz, con el que construir la arquitectura universitaria europea aprobada en Bolonia, a través del constructo de las competencias.

Rev. Diálogo Educ., Curitiba, v. 9, n. 27, p. 215-248, maio/ago. 2009 
se está poniendo un mayor acento en el aprendizaje, con la doble faceta de saber y de saber hacer, de lo cual deriva el acento puesto en las competencias y en la búsqueda de relaciones de competencias/indicadores que sirvan de instrumento normativo y de cotejo, que, por su parte, faciliten la mensurabilidad, la empleabilidad, la movilidad, y las transferencias internacionales; todo esto como medida favorable, por otra parte, a la convergencia entre distintos sistemas educativos nacionales.

Con este propósito, la OCDE, en 1997, puso en marcha el Proyecto DeSeCo (Definition and Selection of Competencies), revisado en el año 2000 y en el 2003, con la intención de construir relaciones de competencias aceptables que puedan servir de indicadores para la evaluación externa de los rendimientos escolares demostrables (como saber hacer). En este proyecto, según Pérez Gómez (2008), se propone un concepto de competencias complejo - no lineal, como el conductista-, dentro de una interpretación comprensiva, constructiva y holística: esto es, como complejos sistemas de reflexión y acción, que incluyen conocimientos, habilidades, valores, actitudes y emociones; un saber hacer complejo, resultado de la integración, movilización y adecuación de capacidades, conocimientos, actitudes y valores, utilizados eficazmente en situaciones reales; un concepto que así dicho se relacionaría con el de "conocimiento práctico" definido por Schön (1983), a la hora de hablar del conocimiento práctico de los profesores. Un saber hacer complejo y adaptativo, dice Pérez Gómez (2008, p. 80).

Ante la existencia de contextos complejos, cambiantes, abiertos e inciertos y ante la necesidad de adaptarse para actuar en ellos de modo autónomo y creativo, ni el dominio de habilidades simples y específicas, como proponía la pedagogía por objetivos, ni la disponibilidad o almacenaje de información serían fundamentales, siendo, en cambio, lo importante el desarrollo de capacidades humanas fundamentales tanto genéricas o transversales, como específicas, para comprender, situarse o intervenir en tales contextos, con énfasis en la metacognición, lo cual debería implicar la introducción de notables cambios en la concepción, diseño y concreción de los currícula y en los métodos de formación y de evaluación al dar prioridad al aprendizaje.

Este enfoque que se pretende dinámico y complejo, alejado del que anteriormente se manejaba y en virtud del que las competencias se entendían como cualidades aisladas, eminentemente cognitivas y predeterminantes del desempeño profesional eficiente, se promueve en el presente como resultado de procesos de aprendizaje que deberían garantizar que los alumnos sean capaces de integrar los conocimientos, las habilidades, las actitudes y los valores que exigen las nuevas situaciones y perfiles profesionales. Así, en estos términos entiende la Unión Europea las competencias profesionales (CONSEJO EUROPEO, 2006) dentro del actual proyecto de reforma curricular universitaria, constituído sobre la base del programa Tuning (2003). Hacia donde habrían de dirigirse ahora los programas de formación del profesorado.

Rev. Diálogo Educ., Curitiba, v. 9, n. 27, p. 215-248, maio/ago. 2009 
Frente a la aparente bondad de la propuesta, la asignación de criterios de ejecución ejemplar a distintas competencias globales, a partir de ejecuciones observables, es en si mismo una operación bien delicada; parte de supuestos positivistas y utilitaristas, con posible olvido de fundamentos éticos; se eliminan competencias de difícil evaluación (ej: "saber razonar con coherencia", "ser solidarios", y otras, que no aparecen por ejemplo en los exámenes PISA promovidos por la OCDE); el socio-constructivismo que se situaba en el corazón del paradigma del profesor reflexivo debe sujetarse aquí a exigencias administrativas procedentes de la "normalización" de aprendizajes y de la misma evaluación; llegando a convertirse las competencias en predictores del éxito profesional posterior, es decir, en un instrumento de meritocracia, al servicio de la estratificación profesional.

En este sentido, siendo numerosos los defensores, no lo son menos los contradictores. Entre ellos, el prestigioso profesor José Gimeno Sacristán muestra su reticencia frente al lenguaje de las competencias, ahora mismo en boga en los actuales textos jurídicos españoles de política educativa. Señala, al respecto, que el término "competencia" no está actualmente delimitado con precisión en el campo educativo (como Basic skills, o como key competencies), apareciendo como un concepto holístico, con significado compartido con otros conceptos, lo cual imposibilita entonces precisar cuántas y cuáles son las competencias educativas. Algo similar sostiene Felix Angulo (2008), al tiempo que señala que la enseñanza/aprendizaje por competencias, a pesar de ser definida como un concepto complejo, es practicada más allá de la retórica de modo mecanicista, pues es "esencialmente trabajar con perfiles profesionales, bajo la justificación de formar profesionales competentes" (ANGULO, 2008, p. 197), haciendo notar además que el modelo parte de que la Universidad debe formar profesionales según los stándares que el mercado laboral exige, lo que entraña la mercantilización de la enseñanza; lo contrario de un saber crítico y emancipatorio. Estaríamos, según su criterio, ante un remix de la pedagogía por objetivos, a la que ahora se añadariría la impronta laboral-profesional.

Por su parte, Torres Santomé (2008) hace notar que en la programación por competencias se obvia el debate sobre los contenidos culturales necesarios y sobre la epistemología. Qué conocimientos son más imprescindibles, cuáles son las funciones del sistema educativo en la actual sociedad diseñada según criterios neo-liberales. Mientras, "la hipertrofia de la práctica contribuye a dejar al profesorado sin apenas preocupación por revisar y contrastar sus marcos teóricos" (SANTOMÉ, 2008, p. 169) y a la espera de que desde el exterior le señalen prescriptivamente las conductas a seguir.

Por todo lo dicho parece que la formación por competencias no debería ser considerada un paradigma adecuado para la formación del profesorado si el horizonte de contraste lo situamos sólo en los perfiles profesionales observables y evaluables, cuando, por el contrario es preciso formar un cuadro complejo con

Rev. Diálogo Educ., Curitiba, v. 9, n. 27, p. 215-248, maio/ago. 2009 
dimensiones reflexivas, investigadoras, interpersonales, creativas, éticas y críticas. La misma Unión Europea y la OCDE parecen, paradójicamente y en alguna medida, conscientes de ello a la vista del Informe EURYDICE (2004) y del Informe de la OCDE (2004), que pueden ser un valioso elemento de contraste para seguir reflexionando, como se hace y con intensidad en el n 340 de la Revista de Educación (2006) ante cuestión tan compleja y de difícil agotamiento.

\section{REFERENCIAS}

ALLEN, D. W. Microenseñanza. Revista de Educación, Madrid, n. 241, p. 45-52, 1975.

ANGULO RASCO, J. F. La voluntad de distracción: las competencias en la Universidad. In: GIMENO SACRISTÁN, J. (Comp.). Educar por competencias, ¿Qué hay de nuevo? Madrid: Morata, 2008. p. 176-205.

ANTUNES, F. A nova orden educativa mundial e a Unión Europea: a formação de profesores; dos Principios comúns ao ángulo portugués. Perspectiva. Revista do Centro de Ciencias da Educação, Florianópolis, v. 25, n. 2, p. 425-468, 2007.

BARQUIN RUÍZ, J. La evolución del pensamiento pedagógico del profesor. Revista de Educación, Madrid, n. 294, p. 245-274, 1991.

. La investigación sobre el profesorado. El estudio de la cuestión. Revista de Educación, Madrid, n. 306, p. 7-66, 1995.

BERNAT MONTESINOS, A. Bases para un curriculum de formación de profesores de Educación General Básica, Revista de Educación, Madrid, n. 269, p. 17-42, 1982.

BOUSQUET, J. ¿Pueden fabricarse profesores? Revista de Educación, Madrid, n. 221-222, p. 3-8, 1972.

La formación del profesorado del siglo XXI. Revista de Educación, Madrid, n. 215-216, p. 63-73, 1971.

CAÑAL DE LEÓN, P.; PORLÁN, R. Una experiencia de aprendizaje por investigación directa del medio en la formación de maestros. Revista de Educación, Madrid, n. 284, p. 273-294, 1987.

COMISIÓN EUROPEA. Educación y formación en Europa: sistemas diferentes, objetivos comunes para 2010. Luxemburgo: Servicio de Publicaciones Oficiales de las Comunidades Europeas. 2002.

Rev. Diálogo Educ., Curitiba, v. 9, n. 27, p. 215-248, maio/ago. 2009 
COMISIÓN OF THE EUROPEAN COMMUNITIES. Common European principles for teacher competentes and qualifications. Bruxelas, 2005a. Disponible en: <http://ec.europa.eu/education/polices/2010/doc/ principles_en.pdf $>$. Acceso en: 14 marzo 2006.

CONSEJO EUROPEO. Recomendación del Parlamento Europeo y del Consejo de 18 de diciembre de 2006 sobre las competencias clave para el aprendizaje permanente. Bruselas: Diario Oficial de la Unión Europea, 30 de diciembre. Disponible en: <http://eurlex.europa.eu/LexUriServ/site/es/oj/2006/l_394/ 1_39420061230es00100018.pdf> Acceso en: 14 marzo 2006.

CONTRERAS DOMINGO, J. ¿El pensamiento o el conocimiento del profesor? Una crítica a los postulados de las investigaciones sobre el pensamiento del profesor y sus implicaciones para la formación del profesorado. Revista de Educación, Madrid, n. 277, p. 5-28, 1985.

. De estudiante a profesor. Socialización y aprendizaje en las prácticas de enseñanza. Revista de Educación, Madrid, n. 282, p. 203-234, 1987.

COSTA RICO, A. El profesorado y la renovación pedagógica en España (19651996). Cadernos de História da Educação, Uberlândia, n. 6, p. 13-38, 2006.

DALE, R. Globalization and education: demonstrating a common World educational culture's or locating a 'globally structured educational agenda'? Educational Theory, v. 50, n. 4, p. 427-448, 2000.

DE LA ORDEN, A. Un problema inaplazable: la formación del profesorado. Revista de Educación, Madrid, n. 269, p. 7-16, 1982.

DICKSON, George E. La formación del profesorado basada en la competencia. Revista de Educación, Madrid, n. 241, p. 24-44, 1975.

DOYLE, W. La investigación sobre el contexto del aula: hacia un conocimiento básico para la práctica y la política de formación del profesorado. Revista de Educación, Madrid, n. 277, p. 29-43, 1985.

ESCUDERO MUÑOZ, J. M. Consideraciones y propuestas sobre la formación del profesorado. Revista de Educación, Madrid, n. 317, p. 11-29, 1998.

ESCUDERO, T.; FERNÁNDEZ URÍA, E. El perfeccionamiento del profesorado en ejercicio. Revista de Educación, Madrid, n. 241, p. 78-91, 1975.

Rev. Diálogo Educ., Curitiba, v. 9, n. 27, p. 215-248, maio/ago. 2009 
EURYDICE/UNIÓN EUROPEA. The teaching profession in Europe: profile, trends and concerns. Report IV: keeping teaching attractive for the $21^{\text {st }}$ century. Brusels, Eurydice. 2004. Disponible en: <http://www.eurydice.org $>$. Acceso em: 14 marzo 2006.

FERNÁNDEZ DE CASTRO, I. Reforma educativa y desarrollo capitalista. Madrid: Cuadernos para el Diálogo, 1973.

FULLAN, M.; HARGREAVES, A. Teacher development and educational change. London: The Falmer Press, 1992.

GETZELS, J.; THELEN, H. A. The dinamic of instructional groups. Annals of National Survey of Student Engement, v. 59, n. 2, p. 80, 1960.

GIMENO SACRISTÁN, J. Diez tesis sobre la aparente utilidad de las competencias en educación. In: GIMENO SACRISTÁN, J. (Comp.). Educar por competencias, ¿qué hay de nuevo? Madrid: Morata, 2008. p. 15-58.

. La formación del profesorado en la Universidad. Revista de Educación, Madrid, n. 269, p. 77-100, 1982.

. Las posibilidades de la investigación educativa en el desarrollo del currículum y de los profesores Revista de Educación, Madrid, n. 284, p. 245272, 1987.

GIROUX, H. A. La formación del profesorado y la ideología del control social (1). Revista de Educación, Madrid, n. 284, p. 53-76, 1987.

HERNÁNDEZ, F. Para aprender del desacuerdo. Cuadernos de Pedagogía, n. 219, p. 73-77, 1993.

HOUSE, E. R. Tres perspectivas de la innovación educativa: tecnología, política y cultura. Revista de Educación, Madrid, n. 286, p. 97-113, 1988.

HOUSTON, R. W. Strategies and resources for developing a competency bassed teacher education program. New York: State Education Department, 1972.

HÜFNER, K. et al. Investigación sobre política educativa comparada: perspectiva de la sociedad mundial. Revista de Educación, Madrid, n. 297, p. 347-402, 1992.

HUSEN, T. El modelo de las escuelas del mañana. Revista de Educación, Madrid, n. 215-216, p. 93-104, 1971.

Rev. Diálogo Educ., Curitiba, v. 9, n. 27, p. 215-248, maio/ago. 2009 
IMBERNÓN, F. ¿Podemos hablar de Freinet en los noventa? Cuadernos de Pedagogía, Barcelona, n. 190, p. 48, 1991.

LERENA ALESON, C. Escuela, ideología y clases sociales en España. Barcelona: Ariel, 1986.

LÓPEZ RUIZ, J. I. Al otro lado de la Academia: el conocimiento empírico del profesorado. Revista de Educación, Madrid, n. 321, p. 245-268, 2000.

LUNDGREN, Ulf. Nuevos desafíos para los profesores y para la formación del profesorado. Revista de Educación, Madrid, n. 285, p. 293-330, 1988.

MARCELO GARCÍA, C. ¿Quién forma al formador? Un estudio sobre las tareas profesionales y necesidades de formación de asesores de Andalucía y Canarias. Revista de Educación, Madrid, n. 313, p. 249-278, 1997.

ORGANISATION FOR ECONOMIC CO-OPERATION AND DEVELOPMENT - OECD. Teachers matter: atracting, developing and retainning effective teachers. París 2004. Disponible en: <www.oecd.org/ dataoecd/38/36/34991371.pdf > . Acceso en: 26 mayo 2006.

OLIVA DELGADO, A. Ideas de educadores preescolares españoles sobre desarrollo y educación infantil. Revista de Educación, Madrid, n. 306, p. 375396, 1995.

OLIVEROS, Á. Balance y perspectivas de la formación de profesores. Revista de Educación, Madrid, n. 241, p. 13, 1975.

. El profesor y la calidad de la educación. Revista de Educación, Madrid, n. 206, p. 12-18, 1969.

PÉREZ GÓMEZ, Á. ¿Competencias o pensamiento práctico? La construcción de los significados de representación y de acción. In: GIMENO SACRISTÁN, J. (Comp.). Educar por competencias, ¿qué hay de nuevo? Madrid: Morata, 2008. p. 59-102.

. El pensamiento del profesor, vínculo entre la teoría y la práctica. Revista de Educación, Madrid, n. 284, p. 199-222, 1987.

RYANS, D. Characteristics of teachers: their description, comparison and appraisal. Washington: American Council of Education, 1967.

SÁNCHEZ GARCÍA, V. La formación de los profesores y las matemáticas. Algunas implicaciones prácticas de las investigaciones teóricas. Revista de Educación, Madrid, n. 306, p. 397-426, 1995.

Rev. Diálogo Educ., Curitiba, v. 9, n. 27, p. 215-248, maio/ago. 2009 
SCHÖN, D. A. Educating the reflective practitionner: toward a new design for teaching and learning in the professions. San Francisco: Jossey-Bas Publishers, 1983.

SHAVELSON, R. J. Review of research on teachers' pedagogical judgements, plans and decisions. The Elementary School Journal, Chicago, v. 83, n. 4, p. 392-413, 1983.

SHULMAN, L. S.; ELSTEIN, A. S. Studies of problem solving, judgment, and decision making: implications for educational research. Review of Research in Education, Washington, n. 3, p. 3-42, 1975.

STENHOUSE, L. El profesor como tema de investigación y desarrollo. Revista de Educación, Madrid, n. 277, p. 43-54, 1985.

. Investigación y desarrollo del curriculum. Madrid: Morata, 1984.

$\mathrm{TABA}, \mathrm{H}$. Teaching strategies and cognitive functioning in elementary school children. San Francisco: San Francisco State College, 1965.

TERHART, E. Formas de saber pedagógico y acción educativa. ¿Qué es lo que forma en la formación del profesorado? Revista de Educación, Madrid, n. 284, p. 133-158, 1987.

TOCHON, F. Nothe de synthèse: recherche sur la pensée des enseignants. Un paradigme à maturité. Revue Française de Pédagogie, Lyon, n. 133, p. 129157, 2000.

TORRES SANTOMÉ, J. Obviando el debate sobre la cultura en el sistema educativo: cómo ser competentes sin conocimiento. In: GIMENO SACRISTÁN, J. (Comp.). Educar por competencias, ¿qué hay de nuevo? Madrid: Morata, 2008. p. 143-175.

VILLAR ANGULO, L. M. et al. El profesor como práctico reflexivo en una cultura de colaboración. Revista de Educación, Madrid, n. 304, p. 227-252, 1994.

YANES GONZÁLEZ, J. La formación del profesorado de secundaria: un espacio desolado. Revista de Educación, Madrid, n. 317, p. 65-80, 1998.

ZEICHNER, K. H. Myths and realities: field-based experiences in preservice teacher education. Journal of Teacher Education, USA, v. 31, n. 6, p. 54-55, 1980.

Alternative paradigma of teacher education. Journal of Teacher Education, USA, v. 34, n. 3, p. 3-9, 1983.

Rev. Diálogo Educ., Curitiba, v. 9, n. 27, p. 215-248, maio/ago. 2009 
Dialéctica de la socialización del profesor. Revista de Educación, Madrid, n. 277, p. 95-126, 1985.

. Enseñanza reflexiva y experiencias de aula en la formación del profesorado. Revista de Educación, Madrid, n. 282, p. 161-190, 1987.

Recebido: 25/01/2009

Received: 01/25/2009

Aprovado: 02/04/2009

Approved: 04/02/2009

Revisado: 22/07/2009

Reviewed: 07/22/2009

Rev. Diálogo Educ., Curitiba, v. 9, n. 27, p. 215-248, maio/ago. 2009 